39.P11

\title{
30-Month Results of Foetal Dopamine Cell Transplantation into the Brains of Parkinsonian Patients
}

\author{
J. Dymecki ${ }^{1}$, M. Zabek ${ }^{2}$, W. Mazurowski ${ }^{2}$, W. Lechowicz ${ }^{1}$, J. Stelma-Ch w $^{3}$ and E. Zawada ${ }^{3}$ \\ ${ }^{1}$ Department of Neuropathology, Institute of Psychiatry and Neurology, Warsaw; ${ }^{2}$ Department of \\ Neurosurgery and ${ }^{3}$ Department of Obstetrics-Gynecology, District Hospital, Warsaw, Poland
}

\begin{abstract}
After many years of experimental studies we obtained permission in 1988 from the Research Ethical Committee of the Medical Academy in Warsaw to perform a series of therapeutic transplantations of human foetal mesencephalic tissue into the brains of patients with Parkinson's disease (PD). We followed NECTAR ethical guidelines for the use of foetal material for transplantation purposes.

Implantations of human foetal dopaminergic cells taken from the ventral part of one mesencephalon of 11-12 week-old foetuses into the head of the caudate nucleus were performed in three PD patients aged 48, 53, and 50 years, respectively. All patients had been suffering from the severe form of PD for about 10-15 years (stage 4/5 according to Hoehn \& Yahr scale) with bradykinesia, rigidity and tremor as the main symptoms. Long-lasting L-dopa therapy resulted in side effects with "ON-OFF" syndrome and dyskinesias.
\end{abstract}

The operations were performed according to Madrazo's microsurgical technique. Implantation of foetal tissue into the caput of the caudate nucleus was carried out by means of an instrument devised by Zabek. One day before the operation immunosuppressive therapy was introduced and continued for 6 postoperative months. A detailed clinical examination was performed before and every 3 months after the operation according to the battery of international tests recommended by CAPIT.

The patients were under post-operational observation lasting 30, 20 and 12 months, respectively. Improvement was observed in all patients starting between 3 and 6 months after operation until the present. Significant increases in movement speed for repeated pronationsupination, finger dexterity and foot lifting tests were found. The speed of walking also increased with decreased rigidity. The "OFF" phase during the day became shorter and less severe; dyskinesias were markedly reduced. Some of the results obtained during the 30-month recovery of patient No. 1 are presented in the following Figure and Table.

It seems that the 30 and 20 months recovery of patients No. 1 and No. 2, respectively, is a long enough term of observation to recommend the benefits of intracerebral transplantations in hopeless patients, who have already exhausted all the other therapeutic possibilities and are conscious that the course of the disease will slowly progress and deteriorate. In all patients recovery was not observed before 3 months after transplantation. Probably, this period of time is necessary for sprouting and creation of a neuronal network between the graft and the host brain. The improvement increased between the 3 rd and 6th months, was still continuing during the following months and reached a stable stage at 9-12 months after the transplantation.

Despite the fact that the doses of L-dopa could not be decreased we observed that the duration of dyskinesias and OFF phase decreased significantly in all cases. It is also worth noting that despite the unilateral DA cell implantation, bilateral motor improvement was found. Our results indicate that foetal grafting seems to be a valuable method for selected parkinsonian patients. However, we should never forget that at present neural transplantation is still an experimental approach. 


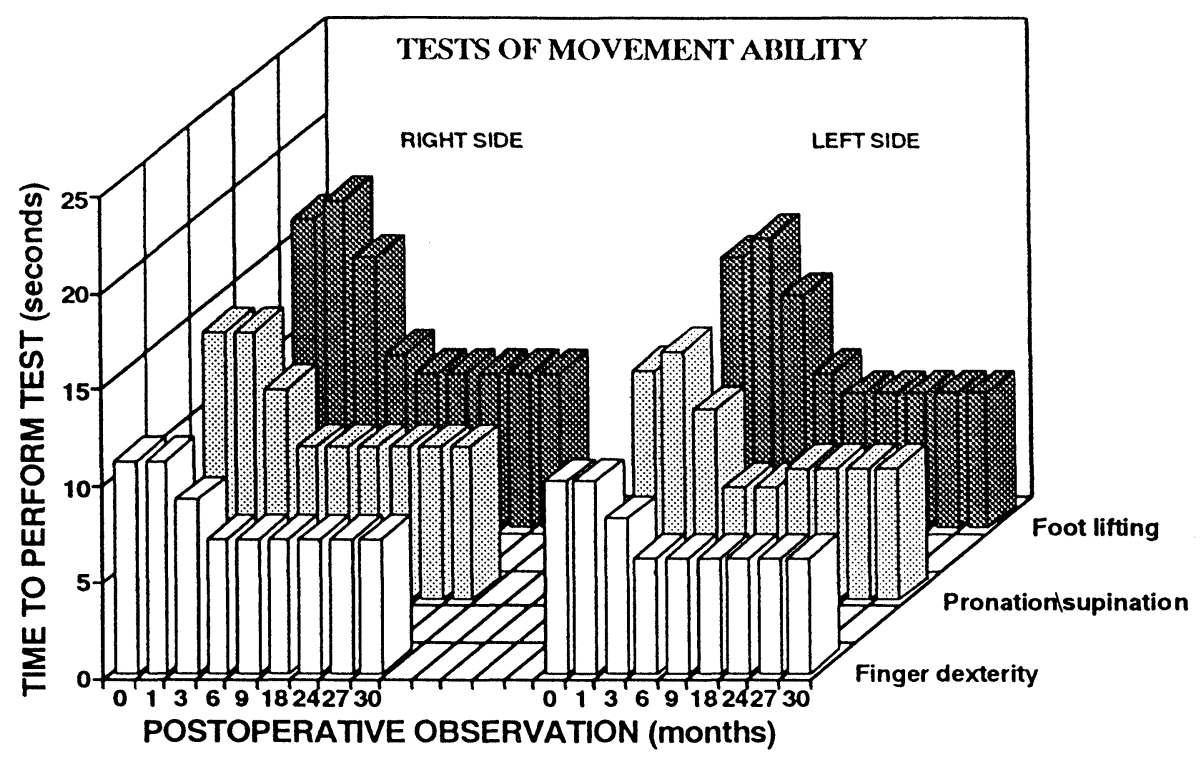

\begin{tabular}{|l|c|c|c|c|c|c|c|c|c|}
\hline & \multicolumn{1}{|c|}{$\begin{array}{c}\text { BEFORE } \\
\text { TRANSPLAN- } \\
\text { EFFECT }\end{array}$} & \multicolumn{7}{|c|}{ MONTHS AFTER TRANSPLANTATION } \\
\cline { 4 - 10 } & 1 & 3 & 6 & 9 & 18 & 24 & 27 & 30 \\
\hline $\begin{array}{l}\text { "OFF" phase } \\
\text { during the day (\%) }\end{array}$ & 55 & 48 & 30 & 20 & 17 & 18 & 18 & 18 & 18 \\
\hline $\begin{array}{l}\text { Duration of } \\
\text { dyskinesias } \\
\text { during the day (\%) }\end{array}$ & 18 & 16 & 15 & 12 & 10 & 11 & 11 & 10 & 10 \\
\hline
\end{tabular}



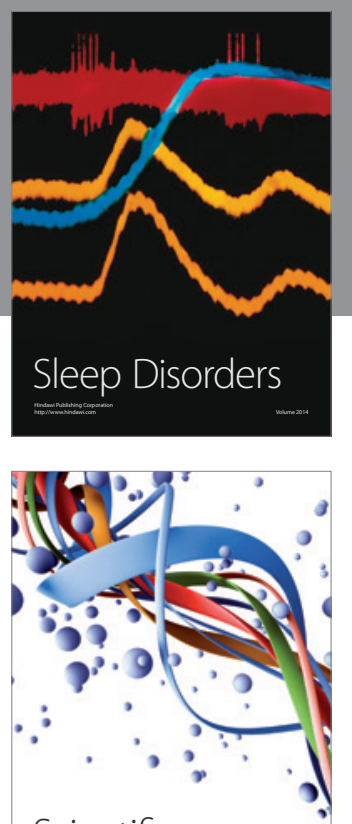

Scientifica
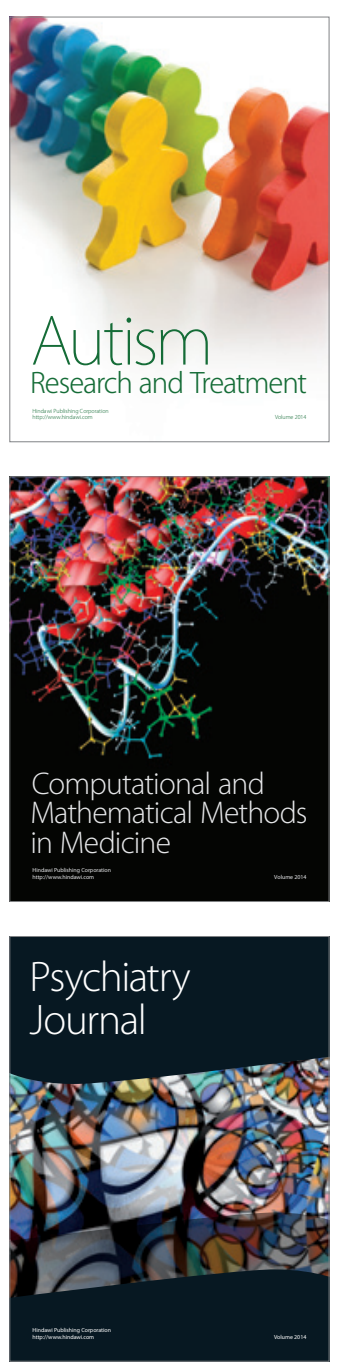
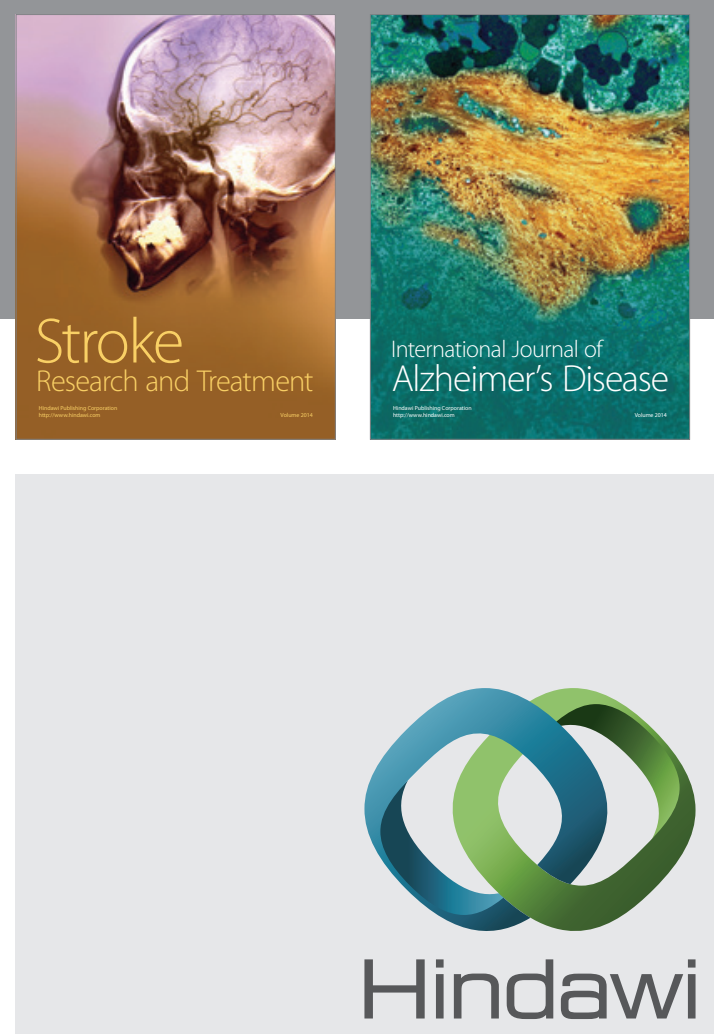

Submit your manuscripts at

http://www.hindawi.com
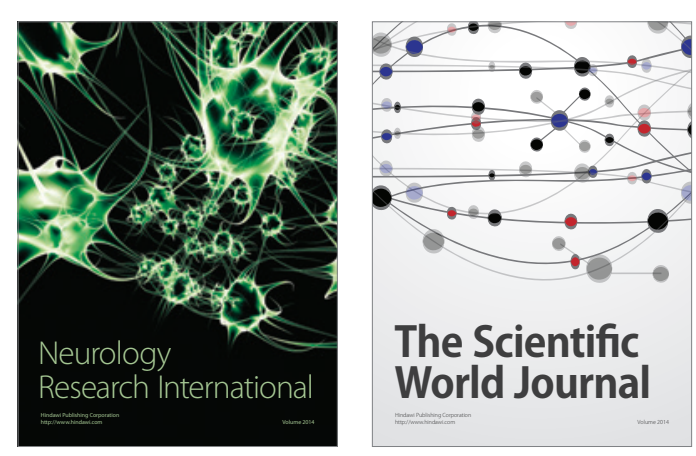

The Scientific World Journal

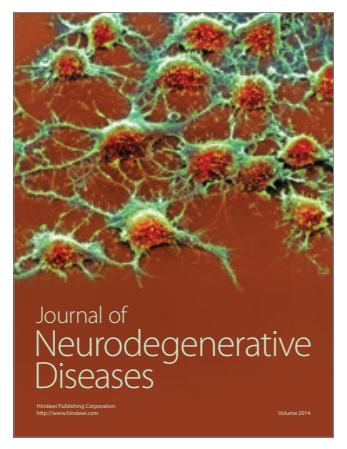

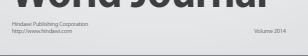

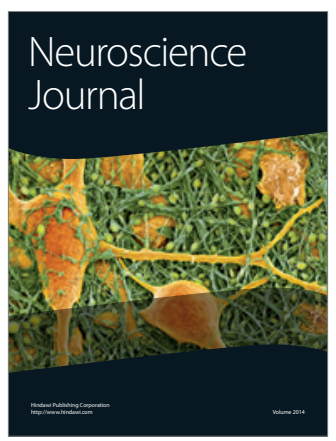

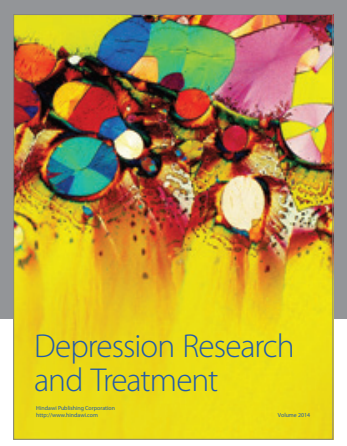
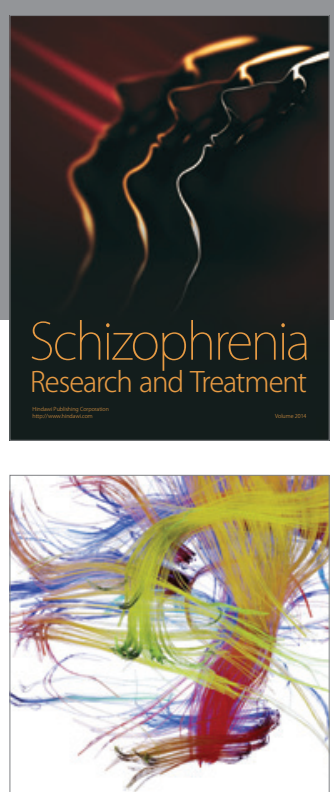

Brain Science

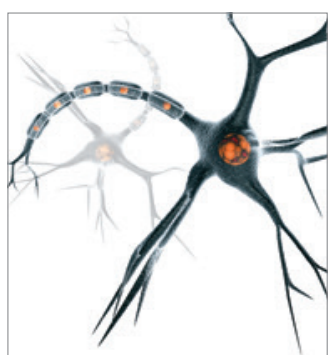

Neural Plasticity
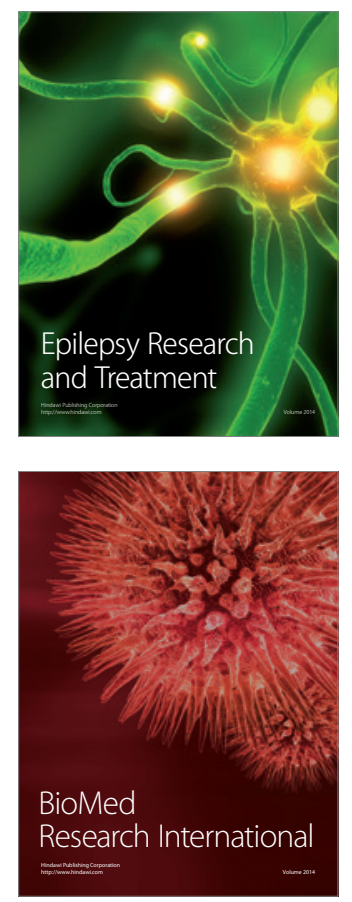

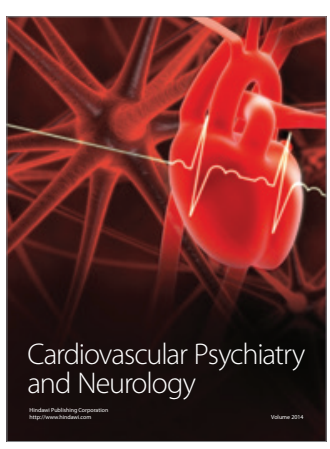

Parkinson's

Disease
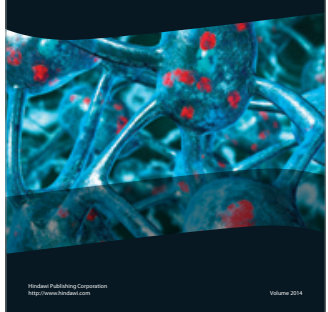